\title{
AUTONOMÍA DE LAS CONFESIONES Y PROFESORES DE RELIGIÓN: EL CASO "FERNÁNDEZ MARTÍNEZ C/ ESPAÑA"1
}

\author{
Gonzalo Castellanos \\ Universidad Católica Argentina, Buenos Aires, Argentina \\ Contacto: gonzalomcastellanos@gmail.com
}

Recibido: 24 de febrero de 2021

Aprobado: 5 de marzo de 2021

Para citar este artículo:

Castellanos, G. (2021). "Autonomía de las confesiones y profesores de religión: El caso 'Fernández Martínez c/ España"”, Prudentia Iuris, N. 91, pp. 225-238 DOI: https://doi.org/10.46553/prudentia.91.2021.pp.225-238

Resumen: Se trata del caso de un profesor de religión y moral católica de un centro docente público en Murcia (España), a quien el Obispado no le renovó el certificado de idoneidad, que le autoriza a ejercer como profesor de religión, debido a que ha mantenido públicamente una conducta y opiniones en abierto contraste con el Magisterio de la Iglesia Católica. Se plantea la autonomía de la Iglesia Católica para juzgar la idoneidad

1 Este artículo corresponde al Proyecto de Investigación IUS 2019/2021, "Libertad religiosa: la objeción de conciencia institucional o el derecho de autonomía de las instituciones y el acomodamiento razonable. Una mirada desde la jurisprudencia nacional y el Derecho Comparado", dirigido por la Dra. Débora Ranieri, Facultad de Derecho, Universidad Católica Argentina. Agradezco a los Dres. María Inés Franck, Débora Ranieri y Nicolás Lafferriere, por los valiosos aportes realizados a este trabajo. 
del profesor de religión, el derecho de no proponer a docentes que han perdido esta cualidad y los estándares de interpretación que surgen del Tribunal Europeo de Derechos Humanos en orden a un legítimo control jurisdiccional.

Palabras clave: Juicio de idoneidad, Autonomía de las confesiones, Control jurisdiccional, Deber de neutralidad estatal. 


\title{
Autonomy of the Confessions and Professors of Religion: The Case "Fernández Martínez v/ España"
}

\begin{abstract}
This is the case of a professor of religion and Catholic morality at a public educational center in Murcia (Spain), whose certificate of suitability was not renewed by the Bishopric, which authorizes him to practice as a religion teacher, due to the fact that has publicly maintained a conduct and opinions in open contrast with the Magisterium of the Catholic Church. It raises the autonomy of the Catholic Church to judge the suitability of the religion teacher, the right not to propose teachers who have lost this quality and the standards of interpretation that arise from the European Court of Human Rights in order to a legitimate jurisdictional control.
\end{abstract}

Keywords: Judgment of suitability, Autonomy of confessions, Jurisdictional control, Duty of state neutrality.

\section{Autonomia delle confessioni e insegnanti di religione: Il caso "Fernández Martínez c/ España"}

Sommario: È il caso di un professore di religione e morale cattolica presso un centro educativo pubblico a Murcia (Spagna), il cui certificato di idoneità non è stato rinnovato dal Vescovado, che lo autorizza a esercitare come insegnante di religione, per il fatto che ha pubblicamente mantenuto una condotta e opinioni in aperto contrasto con il Magistero della Chiesa Cattolica. Solleva l'autonomia della Chiesa cattolica nel giudicare l'idoneità dell'insegnante di religione, il diritto di non proporre insegnanti che abbiano perso questa qualità e gli standard interpretativi che derivano dalla Corte europea dei diritti dell'uomo ai fini di un legittimo controllo giurisdizionale.

Parole chiave: Giudizio di idoneità, Autonomia delle confessioni, Controllo giurisdizionale, Dovere di neutralità dello stato. 


\section{1) Introducción}

El Sr. Fernández Martínez se había desempeñado como profesor de religión católica en un centro docente público de España (Murcia), hasta que el Obispado no le renovó el certificado de idoneidad que lo habilitaba para el ejercicio de dicha función.

A juicio del episcopado, el actor dejó de ser idóneo para la enseñanza religiosa, ya que, por un lado, habiendo sido ordenado sacerdote, solicitó dispensa y, antes de obtener el rescripto, se casó y fue padre de cinco hijos; y, por otro lado, pertenecía al movimiento pro-celibato opcional, defendiendo ideas ajenas a la doctrina católica; todo ello, dado a conocer públicamente en el periódico La Verdad de Murcia.

Fernández Martínez impugnó la no renovación del certificado de idoneidad, transitando diversas etapas de revisión, hasta llegar a la Corte Europea de Derechos Humanos, que juzgó el caso en dos oportunidades, $15 / 5 / 2012$ y $12 / 6 / 2014$.

Nos proponemos abordar el caso, de conformidad al siguiente plan: primero, aproximarnos a la noción de la idoneidad del profesor de religión católica, para cotejar si la decisión del episcopado se ajusta a las normas del Derecho Canónico; y segundo, verificar si el control jurisdiccional ejercido en la especie ha sido respetuoso de la autonomía de la Iglesia Católica en este ámbito.

Nos interesa abordar este tema, pues no es la única vez que se ha sometido a control jurisdiccional el cese de los profesores de religión por pérdida de idoneidad.

En el ámbito europeo, luego del caso "Fernández Martínez c/ España", el Tribunal de Estrasburgo, en fecha 4/10/2016, ha tenido oportunidad de juzgar el caso "Travas c/ Croacia", referido al despido de un profesor de religión, a quien se le retiró la missio canónica para enseñar, debido a que había contraído matrimonio civil estando previamente casado canónicamente con otra persona.

Mientras que, en el ámbito latinoamericano, se presenta el caso "Pavez Pavez, Sandra Cecilia c/ Chile", en donde le negaron a la actora el certificado de idoneidad para enseñar religión, porque el Ordinario del lugar consideró que su orientación sexual era incompatible con la docencia. Este caso cuenta con informe de fondo de la Comisión Interamericana de Derechos Humanos (7/12/2018) y, a la fecha de publicación de este artículo, se encuentra pendiente de resolución ante la Corte Interamericana de Derechos Humanos.

En suma, tratase de casos en los que corresponde delimitar de manera precisa los distintos ámbitos de actuación -civil y religioso-, sin interferencias recíprocas, para que las confesiones religiosas no invadan los asuntos del Estado, y a su vez, el Estado no invada los asuntos de las confesiones religiosas. 


\section{2) Los hechos del caso}

El actor, José Antonio Fernández Martínez, ordenado sacerdote de la Iglesia Católica en 1961, solicitó al Vaticano dispensa de los votos de celibato en el año 1984.

En mayo de 1985, contrajo matrimonio civil, del cual nacieron cinco hijos.

A partir del $1^{\circ}$ de octubre de 1991, el Sr. Fernández Martínez ejerció como profesor de religión y moral católica en un instituto público de Murcia (España), en base a un contrato de trabajo anual renovable, siendo para ello propuesto anualmente por el Obispo de Cartagena.

En noviembre de 1996, el periódico La Verdad de Murcia publicó un artículo sobre el "Movimiento Pro-Celibato Opcional" (MOCEOP). En una fotografía, el demandante aparecía con su esposa y sus cinco hijos con ocasión de una de las reuniones del movimiento, del cual era miembro activo. La crónica se hacía eco de las opiniones de los miembros del movimiento que reclamaban a las autoridades eclesiásticas el celibato opcional, abogando por una Iglesia "más democrática", exponiendo además su desacuerdo con ciertos aspectos del magisterio católico en temas como el aborto, el divorcio, la sexualidad y el control de la natalidad.

En fecha 20 de agosto de 1997, el Santo Padre concedió al actor la dispensa de celibato solicitada trece años atrás. En el rescripto de dispensa se indicaba que el peticionario no podría ser profesor de religión católica en centros educativos públicos a menos que el Obispo así lo autorizase a su prudente juicio, y siempre y cuando no hubiese riesgo de escándalo.

El 29 de septiembre de 1997, la Diócesis de Cartagena comunicó a las autoridades educativas su resolución de no proponer la renovación del contrato del demandante como profesor de religión y moral católica para el año escolar 1997-1998.

Como consecuencia de dicha comunicación, en fecha 9 de octubre de 1997, el Ministerio de Educación hizo saber al hasta entonces maestro que su contrato se daba por finalizado a partir del 29 de septiembre de 1997.

\section{3) Los fallos del Tribunal Europeo de Derechos Humanos}

El Sr. Fernández Martínez inició entonces un procedimiento que fue sorteando sucesivas instancias procesales, siendo el caso juzgado en dos oportunidades por el Tribunal Europeo de Derechos Humanos.

A través de Sentencia del 15/5/2012, el Tribunal Europeo de Derechos Humanos (sección tercera), reunido en Sala, por 6 votos contra 1, declaró 
que no hubo violación al derecho a la vida privada y familiar del accionante (art. $8^{\circ}$ del Convenio Europeo de Derechos Humanos ${ }^{2}$ ).

En tal pronunciamiento, la Sala del Tribunal Europeo apreció que las circunstancias que motivaron la no renovación del contrato del demandante son de naturaleza estrictamente religiosa ${ }^{3}$, añadiendo que en el caso se había quebrado el vínculo de confianza que unía al docente con la Iglesia Católica, no siendo irrazonable exigir una obligación de lealtad acrecentada por parte del profesor de religión ${ }^{4}$.

Contra esta decisión, el afectado solicitó una nueva revisión de la causa ante el Tribunal Europeo de Derechos Humanos.

Por Sentencia de fecha 12/6/2014, el Tribunal Europeo de Derechos Humanos, reunido en Gran Sala, por 9 votos contra 8, declaró que no hubo violación al artículo $8^{\circ}$ del Convenio Europeo de Derechos Humanos y que la injerencia en la vida privada del demandante no fue desproporcionada.

La Gran Sala estimó que el demandante, al firmar sus contratos de trabajo sucesivos, aceptó un deber de lealtad acrecentado hacia la Iglesia Católica, lo que ha limitado, en cierta medida, la extensión de su derecho a la vida privada y familiar, limitaciones semejantes que fueron libremente consentidas ${ }^{5}$.

Seguidamente señaló que, lo que justifica el deber de lealtad acrecentado, resulta del hecho de que para ser creíble, la enseñanza de una religión debe ser realizada por una persona cuyo modo de vida y declaraciones públicas no entren en contradicción flagrante con la religión en cuestión, sobre todo cuando ésta pretende regir la vida privada y las convicciones personales de sus adeptos ${ }^{6}$.

Finalmente, el Tribunal de Estrasburgo afirmó que las autoridades nacionales no pueden pronunciarse sobre el contenido de nociones de carácter religioso, tales como el escándalo o el celibato de los sacerdotes, atento a la autonomía de las comunidades religiosas y al principio de neutralidad religiosa del Estado?

2 Art. $8^{\circ} \mathrm{CEDH}$ : "1. Toda persona tiene derecho al respeto de su vida privada y familiar, de su domicilio y de su correspondencia. 2 . No podrá haber injerencia de la autoridad pública en el ejercicio de este derecho sino en tanto en cuanto esta injerencia esté prevista por la ley y constituya una medida que, en una sociedad democrática, sea necesaria para la seguridad nacional, la seguridad pública, el bienestar económico del país, la defensa del orden y la prevención de las infracciones penales, la protección de la salud o de la moral, o la protección de los derechos y las libertades de los demás".

3 Cfr. punto 84, Sentencia TEDH del 15/5/2012.

4 Cfr. punto 85, Sentencia TEDH del 15/5/2012.

5 Ver punto 135, Sentencia TEDH del 12/6/2014.

6 Ver punto 138, Sentencia TEDH del 12/6/2014.

7 Ver punto 149, Sentencia TEDH del 12/6/2014. 


\section{4) La idoneidad del profesor de religión y el deber de lealtad acrecentado. Canon 804.2 del Código de Derecho Canónico}

El canon 804.2 del Código de Derecho Canónico establece: “[...] cuide el Ordinario del lugar de que los profesores que se destinan a la enseñanza de la religión en las escuelas, incluso en las no católicas, destaquen por su recta doctrina, por el testimonio de su vida cristiana y por su aptitud pedagógica".

De acuerdo a la citada norma canónica, la idoneidad del profesor de religión católica implica tres aspectos: idoneidad doctrinal, idoneidad moral e idoneidad profesional.

La idoneidad doctrinal corresponde a la recta doctrina; la idoneidad moral, al testimonio de vida cristiana; y la idoneidad profesional, a la aptitud pedagógica. Dicho en otros términos, son tres los requisitos que deben cumplir los profesores de enseñanza religiosa católica en las escuelas: dos de índole religiosa (recta doctrina y testimonio de vida cristiana) y uno de naturaleza técnica (aptitud pedagógica) ${ }^{8}$.

$\mathrm{Al}$ respecto, sostiene Precht Pizarro: "En primer lugar, la idoneidad profesional significa contar con las herramientas pedagógicas necesarias para enseñar (en general) y para enseñar Religión (en particular) [...]. En segundo lugar, la idoneidad doctrinal. Es evidente que la autoridad religiosa que emita un certificado de idoneidad debe asegurarse que la enseñanza impartida corresponda a la doctrina oficial de la Religión. Y, en tercer lugar, la idoneidad moral, ya que de toda creencia religiosa (e incluso de una creencia no religiosa) se desprende un comportamiento moral derivado de esa creencia. El docente debe ser coherente con la conducta exigida a los miembros de su Religión. La autoridad religiosa debe velar no solo porque se enseñe una doctrina recta, sino porque el docente sea consecuente, a lo menos, en los puntos más cruciales de esa moral. El docente de Religión no solo enseña con su palabra, sino ante todo con su ejemplo. Lo contrario movería a escándalo"?.

Según Otaduy Guerín, "la idoneidad excede el ámbito de la aptitud profesional, computable mediante titulaciones, méritos y baremos, y su valoración se abre a la esfera de cualidades y circunstancias personales"10.

8 Cfr. Otaduy Guerín, J. (2013). "La idoneidad de los profesores de religión católica y su desarrollo jurisprudencial en España”. Revista Estudios Eclesiásticos, Vol. 88, Nro. 347, 855.

9 Precht Pizarro, J. (2008). "Idoneidad del profesor de religión". Revista Chilena de Derecho, Vol. 35, Nro. 3, 522-523.

10 Otaduy Guerín, J. (2006). "Relación jurídica de los profesores de Religión en España. La dimensión canónica”. Ius Canonicum, Vol. 46, Nro. 92, 467. 
En la misma dirección, Valero Estarellas ha precisado: “[...] corresponde a la Iglesia no sólo la determinación de la capacidad académica o técnica del profesor, sino también la verificación de aquellos aspectos de su vida personal que acrediten un modo de vida acorde con su fe, verificación que excede del ámbito estrictamente profesional y que además se prolonga a lo largo de todo el tiempo que dure la actividad docente"11.

Es decir, la idoneidad canónica del profesor de religión católica comprende la exigencia de brindar recta doctrina, ser testimonio de vida cristiana y contar con aptitud pedagógica, resultando suficiente la ausencia de cualquiera de estos elementos, al inicio o a lo largo de la relación contractual, para determinar la falta de idoneidad del profesor de religión católica.

Es que, como dijo el Superior Tribunal Constitucional Español en Sentencia $\mathrm{N}^{\circ} 38 / 2007$, el juicio de idoneidad no se limita a conocimientos dogmáticos o aptitudes pedagógicas, sino que se extiende al testimonio personal y al ejemplo, "instrumento que la Iglesia puede legítimamente estimar como irrenunciable"12.

En este contexto, Cenalmor y Miras señalan: “[...] es natural que la Iglesia pida ciertas condiciones de idoneidad y de coherencia de vida cristiana a quienes enseñan religión católica; de otro modo, quedaría desvirtuada esa labor por su escasa solidez científica o por la desedificación que supone la vida del profesor"13.

De allí que, a criterio de Fernández Márquez, "la confesión católica puede exigir no sólo que los profesores sepan religión católica sino que sean ellos mismos creyentes y practicantes del catolicismo, de modo que puedan estar en posición de dar ejemplo y dar testimonio de vida católica a los alumnos"14.

Ahora bien, en el caso de Fernández Martínez, la pérdida de la idoneidad del profesor de religión y moral católica se configuró -a nuestro juicioen base a dos motivos: 1) como miembro activo del Movimiento Pro-Celibato Opcional, defendía públicamente ideas que no se ajustaban a la recta doctrina (celibato opcional, Iglesia "más democrática", y desacuerdo en temas como el aborto, el divorcio, la sexualidad y el control de la natalidad); 2) habiéndose ordenado sacerdote, luego como esposo y padre de cinco hijos, no exponía testimonio de vida cristiana.

11 Valero Estarellas, M. J. (2013). "El derecho de los profesores de religión católica al respeto de su vida privada y familiar". Revista General de Derecho Canónico y Derecho Eclesiástico del Estado, Nro. 33, 7.

12 Sentencia STC No 38 del 15/2/2007, punto II-5.

13 Cenalmor, D.; Miras, J. (2004). El Derecho de la Iglesia. Curso básico de Derecho Canónico. Pamplona. Eunsa, 349.

14 Fernández Márquez, O. (2008). "La designación del profesorado de religión y moral católica en centros públicos de enseñanza. Estado de la cuestión tras la STC 38/2007, de 15 de febrero". Revista Española de Derecho Constitucional, Nro. 84, 321. 
Todo ello, dado a conocer públicamente en el artículo publicado en noviembre de 1996 por el periódico La Verdad de Murcia, donde el demandante aparecía en una fotografía con su esposa y sus cinco hijos.

Así las cosas, como expresa Gil y Gil, "lejos de ejercitar un derecho fundamental digno de protección en el caso enjuiciado, el sacerdote se inhabilitó y perdió la idoneidad para el puesto que desempeñaba"15.

En efecto, apunta Gas Aixendri que "la verificación de desviaciones doctrinales manifestadas externamente o de una conducta en objetivo contraste con las enseñanzas de la moral católica comportarán necesariamente la pérdida de la idoneidad y el consecuente acto administrativo de revocación de la acreditación para la enseñanza religiosa por parte de la autoridad eclesiástica"16.

Así pues, tal como aduce Otaduy Guerín, "se comprende que una cierta actitud ejemplar del maestro es inseparable de cualquier proyecto formativo digno de tal nombre [...] La máxima capacidad de arrastre en el terreno ético depende de la coherencia existencial"17.

En el caso sub examine, tal como lo señaló el Tribunal Constitucional Español, la falta de idoneidad del actor para impartir enseñanza religiosa advino como consecuencia de la "disimilitud, desemejanza, falta de sintonía u oposición de la conducta, vida personal u opiniones del demandante de amparo con los postulados definitorios del credo religioso de la Iglesia Católica"18.

Por lo demás, esta exigencia de idoneidad integral justifica una obligación de lealtad acrecentada, conforme a la naturaleza del puesto ocupado y la especificidad de la relación laboral. Es que no es lo mismo ser profesor de Religión que de Matemáticas ${ }^{19}$. Por consiguiente, el incumplimiento de la obligación de lealtad acrecentado supone un quiebre en la relación de confianza entre el Obispo y el docente ${ }^{20}$.

En este sentido, Moreno alega que "en el caso de los profesores de religión, el deber de lealtad y fidelidad exigido en todas las relaciones jurídicas se acrecienta en las actividades en las que los requisitos profesionales y la

15 Gil y Gil, J. L. (2014). "La no renovación del contrato de trabajo de un sacerdote secularizado y casado, profesor de religión y moral católica: comentario a la STEDH de 15 de mayo de 2012, 'Caso Fernández Martínez contra España”, demanda 56030/07. Anuario de Derecho Eclesiástico del Estado, Nro. 30, 251.

16 Gas Aixendri, M. (2012). "La declaración canónica de idoneidad para la enseñanza de la religión católica y su control jurisdiccional por parte del Estado". Revista General de Derecho Canónico y Derecho Eclesiástico del Estado, Nro. 29, 8.

17 Otaduy Guerín, J. (2007). "Idoneidad de los profesores de religión. Una revisión necesaria y urgente. A propósito de la sentencia 38/2007, de 15 de febrero, del Tribunal Constitucional". Revista General de Derecho Canónico y Derecho Eclesiástico del Estado, Nro. 14.

18 Cfr. punto II, 9, Sentencia STC N ${ }^{\circ}$ 128/2007.

19 Ver puntos 90 y 131, Sentencia TEDH del 12/6/2014.

20 Cfr. punto 136, Sentencia TEDH del 12/6/2014. 
conducta privada están íntimamente ligados con el fin de preservar la credibilidad de la Iglesia"21.

De lo hasta aquí considerado, se sigue que el Sr. Fernández Martínez perdió la idoneidad para ejercer como profesor de religión católica, por no ajustar su doctrina y su conducta a las pautas que surgen del canon 804.2 del Código de Derecho Canónico, todo lo cual fue publicado en noviembre de 1996 en el periódico La Verdad de Murcia, incumpliendo el deber de lealtad acrecentado que exige la naturaleza del puesto ocupado.

Por una parte, las desviaciones doctrinales manifestadas externamente por el mismo suponen una escasa solidez científica, en la medida en que las ideas que defendía como miembro del MOCEOP, en temas como el aborto, la sexualidad y el control de la natalidad, no corresponden al Magisterio de la Iglesia Católica ${ }^{22}$.

Por otra parte, el comportamiento moral públicamente manifestado (sacerdote casado) aparecía en objetivo contraste con las enseñanzas de la moral católica, suscitaba escándalo en la comunidad educativa y eclesial e implicaba un modo de vida no acorde con la fe.

En virtud de lo expuesto, siendo que el estatus del demandante (miembro del MOCEOP y sacerdote casado) no se adecuaba a la idoneidad eclesial que prescribe el canon 804.2 del Código de Derecho Canónico, por falta de recta doctrina y de testimonio de vida cristiana, y ante la falta de observancia del deber de lealtad acrecentado que representa un quiebre en la relación de confianza, la no renovación del certificado de idoneidad de profesor de religión católica luce razonable y justificada, ajustándose a las normas canónicas que rigen en la materia.

\section{5) El control jurisdiccional de la remoción del profesor de religión. Canon 805 del Código de Derecho Canónico}

El canon 805 del Código de Derecho Canónico prescribe: "El Ordinario del lugar, dentro de su diócesis, tiene el derecho a nombrar o aprobar los profesores de religión, así como de remover o exigir que sean removidos cuando así lo requiera una razón de religión o moral”.

21 Moreno, G. (2017). "Profesores de religión: tres sentencias y un mismo fallo a favor de la autonomía confesional en el TEDH (un posible paradigma de solución para el caso 'Pavez')". Persona y Derecho, Nro. 77, 295.

22 Sobre el aborto opinaba "es un problema personal y que no debía ser prohibido por la Ley"; acerca del control de la natalidad sostenía "es necesario" y "cada persona debe libremente elegir el método que considere más idóneo", y en relación a la sexualidad expresaba "ni el Papa cree que se pueda uno condenar por ello", cfr. Gil y Gil, J. L. Ob. cit., 247. 
En el caso Fernández Martínez, se observa que la Diócesis de Cartagena ejerció el derecho de remover al profesor de religión, por razones religiosas y morales, ya que la situación personal del actor y su condición de miembro activo del MOCEOP configuraban elementos constitutivos de la pérdida de idoneidad como docente, en virtud de su desviación doctrinal y falta de sintonía con los postulados definitorios del credo católico.

Por consiguiente, tratándose de una decisión eclesiástica basada en motivos religiosos o morales, el control jurisdiccional se halla limitado a verificar la prohibición de arbitrariedad o discriminación y a controlar que no se hayan transgredido los límites del orden público, pues se halla en juego la autonomía de las confesiones, el derecho a la libertad religiosa en su dimensión colectiva y el principio de neutralidad del Estado.

En el caso que nos ocupa, al haberse constatado el carácter religioso y moral de la motivación, no habiendo elementos que permitan suponer que hubo discriminación o arbitrariedad, y encontrándose a salvo el límite del orden público, se observa que el control jurisdiccional ejercido en la especie, que en definitiva implicó el respeto a la decisión del Obispado de Cartagena, se ajusta a la autonomía de las confesiones, al derecho a la libertad religiosa en su faz colectiva y al deber de neutralidad estatal.

Al respecto, López, A. y López, S., precisaron que "la competencia para definir las razones religiosas corresponde, lógicamente, a la Iglesia Católica, no a la Administración educativa ni a los órganos jurisdiccionales, porque así lo exige la aconfesionalidad estatal. Esto no excluye el control jurisdiccional de las decisiones y las razones de la jerarquía eclesiástica. Y este control es posible porque el Ordinario no goza de absoluta discrecionalidad para realizar su juicio de idoneidad, sino que ha de ajustarse a pautas previamente establecidas por la Iglesia, contenidas en los preceptos del Código de Derecho Canónico (cc. 804 y 805) y en las disposiciones en que se concretan los requisitos exigidos [...] Por supuesto, el contenido de estos criterios eclesiásticos, a los que atiende posteriormente el Ordinario para emitir su juicio en el caso concreto, no puede ser objeto de fiscalización pública, pues lo impiden la aconfesionalidad estatal y el derecho de libertad religiosa, a salvo siempre, claro está, el límite del orden público"23.

En efecto, la decisión jurisdiccional ha significado el reconocimiento de la autonomía de la Iglesia Católica, permitiendo el ejercicio de la libertad religiosa en su dimensión colectiva y la posibilidad de que ésta lleve adelante su misión específica, que no es otra que la evangelización ${ }^{24}$, sin inter-

23 López, A.; López, S. (2011). "Virtualidad de la motivación religiosa en la pérdida de idoneidad del profesorado de religión católica”. Ius Canonicum, Nro. 51, 631.

24 Cfr. canon 747.1 del Código de Derecho Canónico. 
ferencia estatal, en una materia que es de su propio resorte y competencia, cual es la referida al juicio de idoneidad que, al resultar negativo, derivó en el cese de Fernández Martínez como profesor de religión.

En este sentido, se ha dicho que "la idoneidad eclesial desde el punto de vista religioso del docente resulta indispensable y sólo la Iglesia puede otorgar el reconocimiento de la misma, pues al Estado se lo veda el principio de neutralidad estatal en este campo"25.

En la misma línea, Martínez Torrón sostiene: “[...] sólo la legítima autoridad eclesiástica puede determinar quién puede enseñar doctrina católica en nombre de la Iglesia, y también quién no puede ya hacerlo. De manera que las autoridades estatales invadirían la legítima autonomía religiosa de la Iglesia Católica, y también violarían el principio de neutralidad estatal, si procedieran a cualquier revisión sustancial de la decisión por la que un obispo decide retirar a una persona el permiso para enseñar religión actuando de acuerdo con el Derecho Canónico y por razones de carácter religioso" 26 .

\section{6) Conclusiones}

En el caso traído a consideración, a partir de las circunstancias particulares que se presentaban, atento a las públicas declaraciones contrarias al Magisterio de la Iglesia y del comportamiento moral llevado por el actor, la autoridad eclesiástica ha juzgado acertadamente la pérdida de idoneidad del mismo por no ajustarse a la recta doctrina y por falta de testimonio de vida cristiana que derivó en la no renovación del contrato como profesor de religión.

No debe perderse de vista que corresponde a las confesiones la competencia para el juicio sobre la idoneidad de las personas que hayan de impartir la enseñanza de su respectivo credo, juicio éste que no se limita a la estricta consideración de los conocimientos dogmáticos o de las aptitudes pedagógicas del personal docente, siendo también posible que se extienda a los extremos de la propia conducta, toda vez que la transmisión encuentra en el ejemplo y el testimonio personal un instrumento que la Iglesia puede legítimamente estimar irrenunciable ${ }^{27}$.

25 Brage Camazano, J. (2007). "La no renovación de contrato a los profesores de Religión en las escuelas públicas por falta de idoneidad canónica (autonomía de las Iglesias y aconfesionalidad del Estado vs. derechos fundamentales del trabajador). Comentario a las SSTC Nros. 38/2007 y 128/2007". Teoría y Realidad Constitucional, Nro. 20, 652-653.

26 Martínez Torrón, J. (2017). "La autonomía religiosa y la vida privada de los profesores de religión en la jurisprudencia de Estrasburgo: el caso 'Fernández Martínez". En Moreno Antón, M. (coord.). Sociedad, Derecho y Factor Religioso. Estudios en honor del profesor Isidoro Martín Sánchez. Granada. Comares, 384.

27 Cfr. Sentencia STC No 38/2007, punto II-5. 
Tal decisión ha sido adecuadamente respetada en la esfera jurisdiccional, ya que se constató el carácter religioso y moral de la motivación y no se ingresó -con razón- en la valoración del acierto o conveniencia del criterio la autoridad religiosa.

$\mathrm{Al}$ no presentarse elementos que permitan suponer que en el caso hubo discriminación o arbitrariedad, estando a salvo el límite del orden público, en virtud del principio de neutralidad religiosa, y frente al incumplimiento del deber de lealtad acrecentado que derivó en el quiebre en la relación de confianza, se concluye que la no renovación del certificado de idoneidad y, por ende, el cese del Sr. Fernández Martínez como profesor de religión, se ajusta a derecho, luce objetivo, razonable y proporcionado a las circunstancias de la causa, tratándose de una decisión respetuosa de la autonomía de la Iglesia Católica en una materia que le es propia y que permite el pleno ejercicio del derecho a la libertad religiosa en su dimensión colectiva.

El Tribunal de Estrasburgo fijó como estándar de interpretación que, cuando se trata de asuntos de naturaleza religiosa (tal es el caso de la idoneidad de los profesores de religión), las autoridades nacionales no pueden pronunciarse sobre el contenido de las decisiones eclesiásticas, en atención a la autonomía de las comunidades religiosas y en virtud del principio de neutralidad del Estado.

De acuerdo a las conclusiones a que arribó la Corte Europea de Derechos Humanos en sus dos fallos, compartimos la opinión de Moreno en el sentido de que "podemos aventurar que se está consolidando una doctrina uniforme que puede ofrecer una cierta seguridad jurídica y que, en definitiva, marca una tendencia en ascenso para proteger la vertiente colectiva del derecho de libertad religiosa y, por ende, la autonomía de las confesiones [...] frente a interferencias externas que bajo el pretexto de la tutela de los derechos fundamentales puedan enturbiar el mensaje religioso que se pretende transmitir"28.

Así pues, cuando se trate de un asunto de jurisdicción y competencia religiosa, como fue este caso vinculado a la remoción del profesor de religión católica por razones religiosas o morales, el Tribunal Europeo de Derechos Humanos ha establecido un estándar de interpretación que protege la autonomía de las confesiones y la libertad religiosa en su dimensión colectiva, cuidando siempre que no se verifique arbitrariedad o discriminación y que se haya respetado el límite del orden público. 


\section{Bibliografía}

Brage Camazano, J. (2007). "La no renovación de contrato a los profesores de Religión en las escuelas públicas por falta de idoneidad canónica (autonomía de las Iglesias y aconfesionalidad del Estado vs. derechos fundamentales del trabajador). Comentario a las SSTC Nros. 38/2007 y 128/2007”. Teoría y Realidad Constitucional, Nro. 20, 633-655.

Cenalmor, D.; Miras, J. (2004). El Derecho de la Iglesia. Curso básico de Derecho Canónico. Pamplona. EUNSA.

Fernández Márquez, O. (2008). "La designación del profesorado de religión y moral católica en centros públicos de enseñanza. Estado de la cuestión tras la STC 38/2007, de 15 de febrero". Revista Española de Derecho Constitucional, Nro. 84, 285-335.

Gas Aixendri, M. (2012). "La declaración canónica de idoneidad para la enseñanza de la religión católica y su control jurisdiccional por parte del Estado”. Revista General de Derecho Canónico y Derecho Eclesiástico del Estado, Nro. 29, 1-17.

Gil y Gil, J. L. (2014). "La no renovación del contrato de trabajo de un sacerdote secularizado y casado, profesor de religión y moral católica: comentario a la STEDH de 15 de mayo de 2012, caso "Fernández Martínez contra España”, demanda 56030/07. Anuario de Derecho Eclesiástico del Estado, Nro. 30, 227-253.

López, A.; López, S. (2011). "Virtualidad de la motivación religiosa en la pérdida de idoneidad del profesorado de religión católica”. Ius Canonicum. Nro. 51, 627-652.

Martínez Torrón, J. (2017). "La autonomía religiosa y la vida privada de los profesores de religión en la jurisprudencia de Estrasburgo: el caso 'Fernández Martínez". En Moreno Antón, M. (coord.). Sociedad, Derecho y Factor Religioso. Estudios en honor del profesor Isidoro Martín Sánchez. Granada. Comares, 373-390.

Moreno, G. (2017). "Profesores de religión: tres sentencias y un mismo fallo a favor de la autonomía confesional en el TEDH (un posible paradigma de solución para el caso 'Pavez')". Persona y Derecho, Nro. 77, 271-308.

Otaduy Guerín, J. (2007). "Idoneidad de los profesores de religión. Una revisión necesaria y urgente. A propósito de la sentencia 38/2007, de 15 de febrero, del Tribunal Constitucional”. Revista General de Derecho Canónico y Derecho Eclesiástico del Estado, Nro. 14.

Otaduy Guerín, J. (2013). "La idoneidad de los profesores de religión católica y su desarrollo jurisprudencial en España”. Revista Estudios Eclesiásticos, Vol. 88, Nro. 347, 849-871.

Otaduy Guerín, J. (2006). "Relación jurídica de los profesores de Religión en España. La dimensión canónica”. Ius Canonicum, Vol. 46, Nro. 92, 445-484.

Precht Pizarro, J. (2008). "Idoneidad del profesor de religión". Revista Chilena de Derecho, Vol. 35, Nro. 3, 521-524.

Valero Estarellas, M. J. (2013). "El derecho de los profesores de religión católica al respeto de su vida privada y familiar". Revista General de Derecho Canónico y Derecho Eclesiástico del Estado, Nro. 33, 1-28. 